\title{
IDENTIFICATION OF RAINFALL DISTRIBUTION IN WEST SUMATERA AND ASSESSMENT OF ITS PARAMETERS USING BAYES METHOD
}

Ferra Yanuar, Putri Trisna Sari, Yudiantri Asdi

Department of Mathematics, Faculty of Mathematics and Natural Sciences, Universitas Andalas

e-mail: ferrayanuar@sci.unand.ac.id

\section{DOI: 10.14710/medstat.13.2.161-169}

\section{Article Info:}

Received: 24 Juli 2019

Accepted: 4 October 2020

Available Online: 28 December 2020

Keywords:

Bayes Method, Maximum

Likelihood Estimation,

Rainfall Data.

\begin{abstract}
One distribution of rainfall data is a lognormal distribution with location parameters $\mu$ and scale parameters $\sigma^{2}$. This study aims to estimate the mean and variance of rainfall data in several selected cities and regencies in West Sumatra. Parameter estimation is estimated by using maximum likelihood estimation (direct method) and Bayes method. This study resulted that the Bayes method produces a better predictive value with a smaller variance value than with direct estimation. It was concluded that the estimation by the Bayes method was a better estimator method than the direct estimation.
\end{abstract}

\section{INTRODUCTION}

A hydrological phenomenon is a very complex phenomenon and will never be fully understood. In hydrology, there is a simple hydrological cycle, one of which is rainfall. Rainfall is the amount of rainwater that falls in an area within a certain time. The unit of rainfall is the height of water per unit of time, such as mm3 / sec, mm3 / hour (Cho et al., 2004; Kurniawan, 2019). An understanding of the average distribution of rainfall is very important, especially for water resource management in an area (Amin et al., 2016; Elly Rosmaini, 2019).

In this research, the distribution of the average rainfall data and its parameter estimation will be determined using direct estimation (maximum likelihood estimator or MLE) and indirect estimation (Bayes method) (Badjana et al., 2017; Heaps et al., 2015; Yosboonruang et al., 2019). In the Bayes method, the model parameters to be estimated are assumed to be random variables that have a certain distribution, which is stated as the prior distribution, while the information regarding the probability density function is expressed in the form of the likelihood function (Aini et al., 2019; Muharisa et al., 2018; Yanuar et al., 2019). The model parameter with Bayes is estimated by determining the posterior distribution which is obtained proportionally from the likelihood distribution and the prior distribution.

In this study, the Bayes method will be used to estimate model parameters from the distribution of the average rainfall data in selected city/regency in West Sumatra.

\section{LITERATURE REVIEW}


The following will describe some of the basic theories related to parameter estimation using the Bayes method, which is used as a reference for this research.

Definition 1 (Eka Putri et al., 2019; Juriah et al., 2019) Let $X$ is a random variable with probability density function $f(x)$, the expectation value of $X$ is:

$$
\mu=E(X)=\sum_{x} x f(x)
$$

for discrete random variable $X$ and

$$
\mu=E(X)=\int_{-\infty}^{\infty} x f(x) d x
$$

for continuous random variable $X$.

Definition 2 (Gratia D 'cunha \& Rao, 2014) A random variable is said to have a Lognormal distribution, which is written as $X \sim L N\left(\mu, \sigma^{2}\right)$ and has probaa bility density function:

$$
f\left(x ; \mu, \sigma^{2}\right)=\left\{\begin{array}{cc}
\frac{1}{\sigma x \sqrt{2 \pi}} \exp \left(-\frac{1}{2}\left(\frac{\ln x-\mu}{\sigma}\right)^{2}\right) & x>0, \mu>0, \sigma^{2}>0 \\
0 & x \leq 0
\end{array}\right.
$$

With $\mu$ is the location parameter and $\sigma$ is the scale parameter.

Definition 3 (Aini et al., 2019) A random variable $X$ is Uniform distribution at interval $a \leq x \leq b$ if its probability density function given by

$$
f(x ; a, b)=\left\{\begin{array}{cc}
\frac{1}{b-a} & a<x<b \\
0 & \text { others }
\end{array}\right.
$$

Definition 4 (Yani et al., 2018; Yanuar et al., 2019) A random variable Y has Inverse Gamma distribution with scale parameter $\omega>0$ and shape parameter $\tau>0$, written as $Y \sim I G(\omega, \tau)$, its probability density function given by

and 0 for others.

$$
f(y ; \omega, \tau)=\frac{\omega^{\tau}}{\Gamma(\tau)} y^{-(\tau+1)} \exp \left(-\frac{\omega}{y}\right) \quad, y>0
$$

Theorem 1 (Yani et al., 2018). Expectation value and variance of Y from Inverse Gamma distribution, written as $Y \sim I G(\omega, \tau)$, given by

$$
E(Y)=\frac{\omega}{\tau-1}, \tau>1 \text { and } \operatorname{Var}(Y)=\frac{\omega^{2}}{(\tau-1)^{2}(\tau-2)}, \tau>2
$$

In this present study, for estimating the mean and variance of the parameter model, we implement two methods, namely the direct estimator with the maximum likelihood estimation method and the Bayes method. In the Bayes method, the subjective information related to parameters (prior distribution) and information of the sample is used in estimating the parameters, namely posterior distribution (Bolstad \& Curran, 2017).

Definition 5 (Aini et al., 2019; Yani et al., 2018). The joint probability density function of $n$ random variables $X_{1}, X_{2}, \ldots, X_{n}$ at values $x_{1}, x_{2}, \ldots, x_{n}$ denoted with $f\left(x_{1}, x_{2}, \ldots, x_{n} \mid \theta\right)$ is known as the likelihood function. If $x_{1}, x_{2}, \ldots, x_{n}$ are known, thus likelihood function of parameter $\theta$ denoted as $L(\theta)$. If $X_{1}, X_{2}, \ldots, X_{n}$ are independent random sample which have $f(\boldsymbol{x} ; \theta)$, so 


$$
L(\theta)=f\left(x_{1} ; \theta\right) f\left(x_{2} ; \theta\right) \ldots f\left(x_{n} ; \theta\right)
$$

This study used the non-informative prior distribution of parameter $\theta, f(\theta)$. The prior distribution $f(\theta)$ is said to be a non-informative prior distribution of parameter $\theta$ if the prior distribution is proportional to the root of Fisher's information (Yanuar et al., 2019)

$$
f(\theta) \propto \sqrt{I(\theta)}
$$

Fisher information of parameter $\theta$ for a random variable $\mathrm{x}=\left(\mathrm{x}_{1}, \mathrm{x}_{2}, \ldots, \mathrm{x}_{\mathrm{n}}\right)$ defined as (Yanuar et al., 2019) :

$$
I(\theta)=-E\left[\frac{\partial^{2}}{\partial \theta^{2}} \ln f(x ; \theta)\right]
$$

Meanwhile, the likelihood function related to sample as written in Definition 2.5. Thus, posterior distribution, $f(\theta \mid x)$ is obtained as following

$$
f(\theta \mid x)=\frac{f(x \mid \theta) f(\theta)}{\int_{-\infty}^{\infty} f(x \mid \theta) f(\theta) d \theta}
$$

Expectation value and variance for $\theta$ are obtained from points estimated for this posterior distribution. Expectation value from posterior distribution $f(\theta \mid x)$ denoted as $\hat{\theta}$, known as Bayes estimator for parameter $\theta$ or mean posterior. Variance value from posterior distribution $f(\theta \mid x)$ denoted as $\operatorname{Var}(\hat{\theta})$, known as variance posterior for parameter $\theta$.

\section{METHODS}

This research used secondary data on the average monthly rainfall data in selected city/regency in West Sumatra from 2010 to 2017. This data set is accessed from West Sumatra's BPS website. The selection of city/regency is based on the availability of information related to data that was needed from this study. Not all city/regency have complete information. The selected city/regency are Pariaman City, Solok City, Payakumbuh City, Pesisir Selatan Regency, Padang Pariaman Regency, and Dhamasraya Regency.

The method of data analysis is a direct estimator or maximum likelihood estimator and Bayes method. This research will explore the estimation method with Bayes estimator theoretically from certain distributed data.

\section{RESULTS}

This section describes theoretical steps to obtain the mean posterior and posterior variance using the Bayes method to be applied to the average rainfall data in several cities/regencies in West Sumatra.

\subsection{Identification of Data Distribution}

The distribution of the average rainfall data is usually lognormal distribution or a Weibull distribution (Amin et al., 2016; Cho et al., 2004; Yosboonruang et al., 2019). Therefore, this study will begin with identifying the distribution for each data group using the Kolmogorov-Smirnov test. The Kolmogorov-Smirnov test was carried out on each group of the average rainfall data, with the hypothesis used:

$\mathrm{H}_{0}$ : Rainfall data in city/regency follows a lognormal distribution

$\mathrm{H}_{1}$ : Rainfall data in city/regency does not follow a lognormal distribution

Based on the calculation of the Kolmogorov-Smirnov test, the p-value obtained was $0.35825,0.33272,0.16636,0.5216,0.53589$, and 0.56391 for Pariaman city, Payakumbuh 
city, Solok city, Dhamasraya Regency, Pesisir Selatan Regency, and Padang Pariaman Regency, respectively. Because each p-value is greater than the significant level 0.05 , the average rainfall data for each city/regency follows a lognormal distribution.

\subsection{Bayesian Inference for Lognormal Distribution.}

This section describes the theoretical derivation of the parameter estimation formula using the Bayes method to produce an estimator formula for the mean posterior and variance posterior.

The form of the likelihood function will be determined in advance from data with a Lognormal distribution. Let $X_{i}, \ldots, X_{n}$ are random variable with Lognormal distribution, written as $X_{i} \sim L N\left(\mu, \sigma^{2}\right)$. Its likelihood function is formulated as following:

$$
\begin{aligned}
L\left(\mu, \sigma^{2}\right) & =\prod_{i=1}^{n} f\left(x_{i} \mid \mu, \sigma^{2}\right) \\
& =\left(\frac{1}{\sigma \sqrt{2 \pi}}\right)^{n} \exp \left[-\frac{1}{2 \sigma^{2}} \sum_{i=1}^{n}\left(\ln x_{i}-\mu\right)^{2}\right] \prod_{i=1}^{n} \frac{1}{x_{i}}
\end{aligned}
$$

Let $\vartheta$ is a random variable which $\vartheta=\left(\mu, \sigma^{2}\right)$. It is assumed that $\mu$ and $\sigma^{2}$ are independent thus $f(\vartheta)=f(\mu) f\left(\sigma^{2}\right)$. To obtain the non-informative prior for $f(\vartheta)$, the noninformative prior distribution for $f(\mu)$ and $f\left(\sigma^{2}\right)$ have to be identified first. The noninformative prior distribution for $f\left(\sigma^{2}\right)$ is formulated by using Jeffrey's method in Equation (3). It's known based on Jeffrey's rule that

$$
f\left(\sigma^{2}\right) \propto \sqrt{I\left(\sigma^{2}\right)} \text { and } I\left(\sigma^{2}\right)=-E\left[\frac{\partial^{2}}{\partial \theta^{2}} \ln f\left(x \mid \mu, \sigma^{2}\right)\right]
$$

Since $\mathrm{X} \sim L N\left(\mu, \sigma^{2}\right)$ with probability density function as denoted by Definition 2 , so that

$$
\frac{\partial^{2} \ln f\left(x_{i} \mid \mu, \sigma^{2}\right)}{\partial\left(\sigma^{2}\right)^{2}}=-\frac{1}{2 \sigma^{4}}-\frac{\left(\ln x_{i}-\mu\right)^{2}}{2 \sigma^{6}}
$$

Then we obtain the Fisher information for $\sigma^{2}$ as follow

$$
I\left(\sigma^{2}\right)=-E\left[-\frac{1}{2 \sigma^{4}}-\frac{\left(\ln x_{i}-\mu\right)^{2}}{2 \sigma^{6}}\right]=-\frac{1}{\sigma^{4}}
$$

The noninformative prior distribution for $f\left(\sigma^{2}\right)$ is given by:

$$
f\left(\sigma^{2}\right)=\sqrt{\left|I\left(\sigma^{2}\right)\right|}=\frac{1}{\sigma^{2}}
$$

Meanwhile, the noninformative prior distribution for $f(\mu)$ is selected as Uniform distribution with $0<\mu<b$. It's assumed that the function interval for uniform distribution is constant. Let $b=1$, so prior distribution for $f(\mu)$ is formulated by:

$$
f(\mu)=\frac{1}{b-0}=1
$$

Thus, the noninformative prior distribution for $f(\vartheta)$ are given by

$$
f(\vartheta)=f\left(\sigma^{2}\right) f(\mu)=\frac{1}{\sigma^{2}}
$$

Then, we have to define the posterior distribution for random variable $\vartheta=\left(\mu, \sigma^{2}\right)$ based on the following formula

$$
f(\vartheta \mid x)=\frac{f(x \mid \vartheta) f(\vartheta)}{\int_{0}^{\infty} \int_{-\infty}^{\infty} f(x \mid \vartheta) f(\vartheta) d \mu d \sigma^{2}}
$$


The formula for $f(x \mid \vartheta) f(\vartheta)$ is based on Equation (5) and Equation (9)

$$
\begin{aligned}
& f(x \mid \vartheta) f(\vartheta) \propto\left(\frac{1}{\sigma \sqrt{2 \pi}}\right)^{n} \exp \left[-\frac{1}{2 \sigma^{2}} \sum_{i=1}^{n}(\ln x-\mu)^{2}\right] \frac{1}{\sigma^{2}} \\
& =\frac{1}{\left(\sigma^{2}\right)^{\frac{n}{2}+1}} \exp \left[-\frac{1}{2 \sigma^{2}}\left(\sum_{i=1}^{n}\left(\ln x_{i}\right)^{2}-\frac{\left(\sum_{i=1}^{n} \ln x_{i}\right)^{2}}{n}+n\left(\mu-\frac{\sum_{i=1}^{n} \ln x_{i}}{n}\right)^{2}\right)\right]
\end{aligned}
$$

Let $\beta=\sum_{i=1}^{n}\left(\ln x_{i}\right)^{2}-\frac{\left(\sum_{i=1}^{n} \ln x_{i}\right)^{2}}{n}$ then

$$
f(x \mid \vartheta) f(\vartheta)=\frac{1}{\left(\sigma^{2}\right)^{\frac{n}{2}+1}} \exp \left[-\frac{\beta}{2 \sigma^{2}}\right] \exp \left[-\frac{n}{2 \sigma^{2}}\left(\mu-\frac{\sum_{i=1}^{n} \ln x_{i}}{n}\right)^{2}\right]
$$

Afterward, we will identify the formula for $f(x)=\int_{0}^{\infty} \int_{-\infty}^{\infty} f(x \mid \vartheta) f(\vartheta) d \mu d \sigma^{2}$. First, integral the Equation (11) respect to $\mu$

$$
\begin{aligned}
\int_{-\infty}^{\infty} f(x \mid \vartheta) f(\vartheta) d \mu & =\int_{-\infty}^{\infty} \frac{\exp \left[-\frac{\beta}{2 \sigma^{2}}\right]}{\left(\sigma^{2}\right)^{\frac{n}{2}+1}} \exp \left[-\frac{n}{2 \sigma^{2}}\left(\mu-\frac{\sum_{i=1}^{n} \ln x_{i}}{n}\right)^{2}\right] d \mu \\
& =\sqrt{\frac{2 \pi}{n}}\left(\sigma^{2}\right)^{-\left(\frac{n+1}{2}\right)} \exp \left[-\frac{\beta}{2 \sigma^{2}}\right]
\end{aligned}
$$

Then, integral the Equation (12) respect to $\sigma^{2}$

$$
\begin{aligned}
& f(x)=\int_{0}^{\infty} \sqrt{\frac{2 \pi}{n}}\left(\sigma^{2}\right)^{-\left(\frac{n+1}{2}\right)} \exp \left[-\frac{\beta}{2 \sigma^{2}}\right] d \sigma^{2} \\
& =\sqrt{\frac{2 \pi}{n}}\left(\frac{\beta}{2}\right)^{-\left(\frac{n-1}{2}\right)} \Gamma\left(\frac{n-1}{2}\right)
\end{aligned}
$$

Therefore, we find the posterior distribution for random variable $\vartheta$ by substituting Equation (11) and Equation (13) to Equation (10) as follows

$$
\begin{aligned}
& f(\vartheta \mid x) \propto \frac{\frac{1}{\left(\sigma^{2}\right)^{\frac{n}{2}+1}} \exp \left[-\frac{\beta}{2 \sigma^{2}}\right] \exp \left[-\frac{n}{2 \sigma^{2}}\left(\mu-\frac{\sum_{i=1}^{n} \ln x_{i}}{n}\right)^{2}\right]}{\sqrt{\frac{2 \pi}{n}\left(\frac{\beta}{2}\right)^{-\left(\frac{n-1}{2}\right)} \Gamma\left(\frac{n-1}{2}\right)}} \\
& =\frac{\sqrt{\frac{n}{2 \pi}}\left(\frac{\beta}{2}\right)^{\left(\frac{n-1}{2}\right)}}{\left(\sigma^{2}\right)^{\frac{n}{2}+1} \Gamma\left(\frac{n-1}{2}\right)} \exp \left[-\frac{\beta}{2 \sigma^{2}}\right] \exp \left[-\frac{n}{2 \sigma^{2}}\left(\mu-\frac{\sum_{i=1}^{n} \ln x_{i}}{n}\right)^{2}\right]
\end{aligned}
$$

Equation (14) is a joint posterior distribution for $\mu$ and $\sigma^{2}$, since $\vartheta=\left(\mu, \sigma^{2}\right)$. Hence, we then identify the marginal posterior distribution for $\mu$ and $\sigma^{2}$. To find the marginal posterior distribution for $\mu$ is by integral the Equation (14) with respect to $\sigma^{2}$ as follow 


$$
\begin{aligned}
& f(\mu \mid x) \propto \int_{0}^{\infty} \frac{\sqrt{\frac{n}{2 \pi}}\left(\frac{\beta}{2}\right)^{\left(\frac{n-1}{2}\right)}}{\left(\sigma^{2}\right)^{\frac{n}{2}+1} \Gamma\left(\frac{n-1}{2}\right)} \exp \left[-\frac{\beta+n\left(\mu-\frac{\sum_{i=1}^{n} \ln x_{i}}{n}\right)^{2}}{2 \sigma^{2}}\right] d \sigma^{2} \\
& =\frac{\sqrt{\frac{n}{\beta}}}{\mathrm{B}\left(\frac{1}{2}, \frac{n-1}{2}\right)\left(1+\frac{n}{\beta}\left(\mu-\frac{\sum_{i=1}^{n} \ln x_{i}}{n}\right)^{2}\right)^{\frac{n}{2}}}
\end{aligned}
$$

The point estimate for $\mu$ or mean posterior is obtained from

$$
\begin{aligned}
\hat{\mu}_{\text {Bayes }} & =E(\mu \mid x)=\int_{-\infty}^{\infty} \frac{\sqrt{\frac{n}{\beta}} \mu}{\mathrm{B}\left(\frac{1}{2}, \frac{n-1}{2}\right)\left(1+\frac{n}{\beta}\left(\mu-\frac{\sum_{i=1}^{n} \ln x_{i}}{n}\right)^{2}\right)^{\frac{n}{2}}} d \mu \\
& =\frac{\sum_{i=1}^{n} \ln x_{i}}{\mathrm{n}}
\end{aligned}
$$

The meanwhile marginal posterior distribution for $\sigma^{2}$ is resulted by integral Equation (14) respect to $\mu$ as following

$$
\begin{aligned}
& f\left(\sigma^{2} \mid x\right) \propto \int_{-\infty}^{\infty} \frac{\sqrt{\frac{n}{2 \pi}}\left(\frac{\beta}{2}\right)^{\left(\frac{n-1}{2}\right)} \exp \left[-\frac{\beta}{2 \sigma^{2}}\right]}{\left(\sigma^{2}\right)^{\frac{n}{2}+1} \Gamma\left(\frac{n-1}{2}\right)} \exp \left[-\frac{n\left(\mu-\frac{\sum_{i=1}^{n} \ln x_{i}}{n}\right)^{2}}{2 \sigma^{2}}\right] d \mu \\
& =\frac{\left(\frac{\beta}{2}\right)^{\left(\frac{n-1}{2}\right)}}{\Gamma\left(\frac{n-1}{2}\right)}\left(\sigma^{2}\right)^{-\left(\frac{n-1}{2}+1\right)} \exp \left[-\frac{\beta}{2 \sigma^{2}}\right]
\end{aligned}
$$

It can be seen that Equation (16) identic with Inverse Gamma distribution with parameter $\tau=(\mathrm{n}-1) / 2$ and $\omega=\beta / 2$, written as:

$$
\sigma^{2} \mid x \sim I G\left(\frac{n-1}{2}, \frac{\beta}{2}\right)
$$

Therefore, the mean posterior for $\sigma^{2} \mid \boldsymbol{x}$ is denoted

$$
{\widehat{\sigma^{2}}}_{\text {Bayes }}=E\left(\sigma^{2} \mid x\right)=\frac{\beta}{n-3}
$$

\subsection{The Estimates of Mean and Variance of Rainfall in Selected Regencies / Cities in West Sumatra}

This section will apply the formula obtained in the previous section to estimate the mean and variance of rainfall in several cities and districts in West Sumatra, i.e., Pariaman City, Solok City, Payakumbuh City, Pesisir Selatan Regency, Padang Pariaman Regency, and Dhamasraya Regency. Table 1 below shows the value of the estimation results based on the direct method and the Bayes method. We implemented WinBUGS version 1.4.3 to estimate the parameter model (Ntzoufras, 2009) 
Table 1. The Estimates of Mean and Variance Posterior Using MLE and Bayes Method

\begin{tabular}{clcccc}
\hline \multirow{2}{*}{ No } & \multicolumn{2}{c}{ City/Regency } & \multicolumn{2}{c}{ MLE method } & \multicolumn{2}{c}{ Bayes Method } \\
\cline { 3 - 6 } & & $\hat{\mu}$ & $\hat{\sigma}^{2}$ & $\hat{\mu}_{\text {Bayes }}$ & $\hat{\sigma}^{2}$ Bayes \\
\hline 1 & Pariaman City & 5.674 & 0.245 & 5.674 & 0.245 \\
2 & Solok City & 5.044 & 0.971 & 5.044 & 0.487 \\
3 & Payakumbuh City & 4.781 & 1.519 & 4.782 & 0.598 \\
4 & Pesisir Selatan Regency & 5.382 & 0.341 & 5.382 & 0.213 \\
5 & Padang Pariaman Regency & 5.774 & 0.186 & 5.774 & 0.186 \\
6 & Dhamasraya Regency & 4.918 & 1.329 & 4.919 & 0.658 \\
\hline
\end{tabular}

Based on the table above, it can be seen that the mean posterior estimated obtained from both methods yield almost the same values for all six areas. While the variance posterior estimated based on the Bayes method result in smaller values than the MLE method. This result informs us that the Bayes method tends to yield more accurate values than the direct method. We could conclude that the Bayes method results in better estimated values than MLE (direct method).

From this research, it was known that the highest average rainfall is in Padang Pariaman Regency, which is 5.777, and the lowest is in Payakumbuh City, which is 4.782 .

\section{CONCLUSIONS}

This article implements the Bayes method to estimate the parameters of a particular distribution with a case study to estimate the average rainfall in several cities and districts in West Sumatra. The results obtained from the Bayes method were then compared with the MLE method (direct method). By using the Kolmogorov-Smirnov test at the significant alpha is 5\%, it is known that the average rainfall data for selected cities and districts in West Sumatra from 2010 to 2017 follows the Lognormal distribution with parameter $\mu$ and $\sigma^{2}$.

The formulas to estimate mean posterior for parameter $\mu\left(\hat{\mu}_{\text {Bayes }}\right)$ and variance posterior for parameter $\sigma^{2}\left(\hat{\sigma}^{2}{ }_{\text {Bayes }}\right)$ based on the Bayes method are respectively

$$
\hat{\mu}_{\text {Bayes }}=\frac{\sum_{i=1}^{n} \ln x_{i}}{\mathrm{n}} \text { and } \widehat{\sigma}_{\text {Bayes }}^{2}=\frac{\beta}{n-3}
$$

These formulas are then applied to the secondary data related to the average rainfall in several cities and districts in West Sumatra. This study found that the estimation for the average value at all selected cities and regencies resulted in almost the same values but variance posterior is different. Bayes method produces a smaller estimated value than the direct estimator. This study also informs that the highest average rainfall is in Padang Pariaman Regency, which is 5.777 and the lowest is in Payakumbuh city, which is 4.782.

\section{REFERENCES}

Aini, Z., Yanuar, F., \& Rahmi HG, I. (2019). Penentuan Reliabilitas dari Sistem Berdistribusi Weibull dengan Metode Bayes. Jurnal Matematika UNAND, VIII(1), 332-340.

Amin, M. T., Rizwan, M., \& Alazba, A. A. (2016). A Best-Fit Probability Distribution for the Estimation of Rainfall in Northern Regions of Pakistan. Open Life Sciences, 11(1), 432-440. https://doi.org/10.1515/biol-2016-0057

Badjana, H. M., Renard, B., Helmschrot, J., Edjamé, K. S., Afouda, A., \& Wala, K. (2017). Bayesian Trend Analysis in Annual Rainfall Total, Duration, and Maximum in the 
Kara River basin (West Africa). Journal of Hydrology: Regional Studies, 13, 255273. https://doi.org/10.1016/j.ejrh.2017.08.009

Bolstad, W. M., \& Curran, J. M. (2017). Introduction to Bayesian Statistics (Third Edition). John Wiley \& Sons, Inc.

Cho, H.-K., Bowman, K. P., \& North, G. R. (2004). A Comparison of Gamma and Lognormal Distributions for Characterizing Satellite Rain Rates from the Tropical Rainfall Measuring Mission. Journal of Applied Meteorology, 43(11), 1586-1597. https://doi.org/10.1175/JAM2165.1

Eka Putri, N. C., Yanuar, F., \& Yozza, H. (2019). Metode Bayes Empirik Untuk Memodelkan Data Cacahan Dengan Peubah Penyerta Pada Pendugaan Area Kecil. Jurnal Matematika UNAND, VIII(1), 224-231.

Elly Rosmaini. (2019). Probability Distribution of Rainfall in Medan. Journal of Research in Mathematics Trends and Technology, 1(2), 43-49. https://doi.org/10.32734/ jormtt.v1i2.2835

Gratia D 'cunha, J., \& Rao, K. A. (2014). Bayesian Inference for Mean of the Lognormal Distribution. International Journal of Scientific and Research Publications, 4(10), $1-9$.

Heaps, S. E., Boys, R. J., \& Farrow, M. (2015). Bayesian Modelling of Rainfall Data by using Non-Homogeneous Hidden Markov Models and Latent Gaussian Variables. Journal of the Royal Statistical Society: Series C (Applied Statistics), 64(3), 543568. https://doi.org/10.1111/rssc.12094

Juriah, S., Yanuar, F., \& Yozza, H. (2019). Pendugaan Penyebaran Penyakit Demam Berdarah Dengue (DBD) di Kota Padang. Jurnal Matematika UNAND, VIII(1), 313317.

Kurniawan, V. (2019). Distribution Fitting on Rainfall Data in Jakarta. IOP Conference Series: Materials Science and Engineering, 650, 012060. https://doi.org/10.1088/ 1757-899X/650/1/012060

Muharisa, C., Yanuar, F., \& Devianto, D. (2018). Simulation Study The Using of Bayesian Quantile Regression in Nonnormal Error. CAUCHY, 5(3), 121. https://doi.org/ 10.18860/ca.v5i3.5633

Ntzoufras, I. (2009). Bayesian Modeling using WinBUGS. Wiley.

Yani, R. N., Yanuar, F., \& Yozza, H. (2018). Inferensi Bayesian untuk Variansi dari Distribusi Normal dengan Berbagai Distribusi Prior. Jurnal Matematika UNAND, 7(2), 132-139.

Yanuar, F., Yozza, H., \& Rescha, R. V. (2019). Comparison of Two Priors in Bayesian Estimation for Parameter of Weibull Distribution. Science and Technology Indonesia, 4(3), 82. https://doi.org/10.26554/sti.2019.4.3.82-87 
Yosboonruang, N., Niwitpong, S., \& Niwitpong, S. (2019). Measuring the Dispersion of Rainfall using Bayesian Confidence Intervals for Coefficient of Variation of DeltaLognormal Distribution: A Study from Thailand. PeerJ, 7, e7344. https://doi.org/10.7717/peerj.7344 